\title{
Transcriptional competence in pluripotency
}

\author{
Edupuganti V.S. Raghu Ram and Eran Meshorer ${ }^{1}$ \\ Department of Genetics, The Institute of Life Sciences, The Hebrew University of Jerusalem, Jerusalem 91904, Israel
}

Embryonic stem (ES) cells possess a globally open, decondensed chromatin structure that, together with transacting factors, supports transcriptional competence of developmentally regulated genes. However, our understanding of the mechanisms that establish transcriptional competence of specific genes is limited. In this issue of Genes \& Development, $\mathrm{Xu}$ and colleagues (pp. 28242838) show that tissue-specific enhancers are actively marked by an unmethylated window in ES cells and induced pluripotent stem (iPS) cells. They propose a model and present supporting evidence to demonstrate the active involvement of pioneer transcription factors in this process. This work marks an important step toward the understanding of the mechanisms that define and maintain pluripotency, and calls for the identification of the factors that participate in the establishment of transcriptional competence in pluripotent cells.

Transcription regulation is a complex biological process that occurs in all living cells to respond to diverse external stimuli and to coordinate their inherent cellular programs. Transcription regulation is achieved by the combinatorial integration of several inputs at promoter sites and interactions between different genomic elements such as promoters, enhancers, insulators, and silencers. Numerous interactions between these ciselements and trans-acting proteins form transcription factor networks that, by and large, govern the cellular state of the cell. In embryonic stem (ES) cells, the core transcriptional circuitry has been largely identified (Walker et al. 2007; Chen et al. 2008; Niwa et al. 2009), revealing both master regulators (e.g., Oct4, Sox2, etc.) and signaling pathways (e.g., LIF, BMP, etc.) as controlling pluripotency and self-renewal.

Multiple studies have aimed to identify the minimal set of genes that define "stemness" (Efroni et al. 2009). Although no strong consensus has been reached, it seems that the list of key transcription factors has been reasonably narrowed down to a handful of genes (Kim et al.

[Keywords: Embryonic stem cells; induced pluripotent stem cells; DNA methylation; chromatin; transcription]

${ }^{1}$ Corresponding author.

E-MAIL meshorer@cc.huji.ac.il; FAX 972-2-6586975.

Article is online at http://www.genesdev.org/cgi/doi/10.1101/gad.1881609.
2008). Remarkably, reprogramming studies using combinations of these factors yielded fully reprogrammed cells from somatic cells with only four factors. Several laboratories narrowed this short list even further, demonstrating that each of the four factors can be dispensable under appropriate conditions and/or cell types (Hochedlinger and Plath 2009).

Pluripotency entails the epigenetic resetting of the genome. It is therefore not surprising that it is governed, to a large extent, by chromatin-related mechanisms. Pluripotent cells are characterized by a global, pervasive transcriptional program (Efroni et al. 2008) and distinct chromatin and nuclear properties, which distinguishes them from differentiated cells (Meshorer and Misteli 2006; Meshorer 2008; Sha and Boyer 2009). But which mechanisms enable transcriptional competence in pluripotent cells? Xu et al. (2009) now provide evidence that marking of enhancers seems to be a part of the answer.

\section{Transcription regulation in ES cells}

\section{Alliance of promoters and enhancers drives transcription}

Transcription factors act on promoters and enhancers, often as part of a complex interaction network, to bring about gene activity. Since promoters are the launching pads for RNA polymerase II (RNAPII) as well as the providers of transcriptional start sites, promoters function as key control points for gene regulation and the focal point for a multitude of different epigenetic modifications. Promoters of silent developmental regulator genes in ES cells are characterized by bivalent domains consisting of functionally opposite histone marks: H3K4 trimethylation (H3K4me3) and H3K27me3. Although not unique to ES cells, the bivalent marks seem to play a special role in differentiating cells, keeping developmental genes in a poised state for differentiation (Azuara et al. 2006; Bernstein et al. 2006; Pan et al. 2007). In many protein-coding genes, alternative promoters are often used in a developmental stage- or a tissue-specific manner, significantly increasing transcriptional complexity (Sandelin et al. 2007). In a genomic study of ES and somatic human cells, it was found that transcription is initiated at the majority of all promoters, including transcriptionally inactive genes (Guenther et al. 2007). 
These findings suggest that basal promoter activity might be important for additional cellular functions in addition to turning genes on and off. One attractive possibility, for example, is maintaining a decondensed chromatin conformation at gene sites by recruiting factors that prevent chromatin condensation, or simply by allowing basal transcription.

Promoters often act in conjunction with enhancers. Enhancers are DNA sequences that activate cognate promoters and regulate gene expression in an orientationand position-independent manner (Heintzman and Ren 2009). They are also proposed to function as nucleation centers for the recruitment of general transcription factors (Szutorisz et al. 2005). Enhancers are often characterized by the presence of DNase I-hypersensitive sites (DHSs), and they typically contain combinations of binding sites for different transcriptional regulators, primarily driving tissue-specific gene expression. Epigenetic modifications associated with enhancers include mono-, di-, and trimethylated H3K4, H3K9me1, and acetylated H3K27. But unlike promoters, which show a surprising degree of epigenetic stability across different cell types, histone modifications at enhancers seem to be cell type-specific (Barski et al. 2007; Heintzman and Ren 2009).

The classical model of enhancer action depicts enhancerbound proteins interacting with promoter-associated proteins, bringing the two elements together to regulate gene expression. How enhancers influence the rate of gene expression is not entirely clear. Several different models, not mutually exclusive, were proposed to explain the known enhancer activities (Blackwood and Kadonaga 1998). These models range from an "On/Off" switch to progressive responses of enhancer activity. The former is of particular interest from a stem cell point of view, suggesting that enhancers function in a stochastic manner to increase the transcription probability of a cognate gene (Blackwood and Kadonaga 1998; Fiering et al. 2000).

\section{Pioneer transcription factors have special roles in development}

One particular group of transcription factors-called "pioneer factors"-is essential during early development. Pioneer factors have the ability to interact with packed chromatin at silent genes and establish transcriptional competence during early development (Zaret 2002). Importantly, they can penetrate the repressive chromatin and bind enhancers of tissue-specific genes, marking them for activation at a later developmental stage. Some members of the Fox (Forkhead box) family of transcription factors fall into this group, as they are the first to interact with silent genes and generate transcriptional competence (Zaret 2002; Cairns 2009). One prominent member of the Fox family is FoxD3. FoxD3 is involved in fate choice decisions and differentiation, and has also been implicated in the maintenance of pluripotency (Hanna et al. 2002). Xu et al. (2009) now show that this factor has another important function as a pioneer factor in the formation of an unmethylated window at certain tissue-specific gene enhancers, and implicate it in the generation of transcriptional competence (see below).

It will be interesting to see how these pioneer factors gain access to chromatin in the first place. One clue may lie in the fact that, in general, although not always, binding sites for these pioneer factors are nucleosomedepleted, facilitating their access to chromatin /Cairns 2009). There might be other potential access mechanisms. For example, ATP-independent opening of condensed chromatin was observed in the case of the Albumin gene enhancer by HNF3 (FoxA) and GATA-4. These factors recognize high-affinity DNA-binding sites and open the local nucleosome domain of the enhancer (Cirillo et al. 2002). It is also likely that ATP-dependent chromatin remodeling takes place once the pioneer factor binds its site and exposes others (Cairns 2009). The abundance of chromatin remodelers in ES cells, as noted below, may possibly explain enhancer accessibility in ES cells.

\section{Generation of transcriptional competence}

\section{Transcription in ES cells is global and pervasive}

ES cells are characterized by a globally open chromatin and a pervasive transcriptional program (Meshorer et al. 2006; Efroni et al. 2008, 2009; Bhattacharya et al. 2009). They display elevated levels of transcription across their genome and express normally silent regions and tissuespecific genes at low levels. Supporting this view, undifferentiated ES cells seem to possess elevated levels of general transcription factors and chromatin remodeling proteins (Efroni et al. 2008), some of which interact to form an ES cell-specific chromatin remodeling complex (Ho et al. 2009). Depleting several different remodelers severely affects ES cell self-renewal, differentiation capacity, and pluripotency (Efroni et al. 2008; Fazzio et al. 2008; Yan et al. 2008; Gaspar-Maia et al. 2009; Ho et al. 2009), demonstrating their crucial role in maintaining the stem cell state.

The low-level expression observed in ES cells across their genome (Efroni et al. 2008) can be regarded as transcriptional "noise." Whether transcriptional noise is a mere byproduct of the chromatin conformation or whether it can be used by the cell for its advantage remains an open question (Efroni et al. 2009). Also, whether biological noise contributes to cell lineage or cell fate decisions has been debated (Chang et al. 2008; Kalmar et al. 2009). Although the suggestion that permissive noisy transcription might have some function in the maintenance of ES cell pluripotency is appealing, functional evidence for this is lacking. It has been suggested that an open chromatin state in pluripotent cells is maintained by this permissive transcription (Efroni et al. 2009), but whether open chromatin is a cause or consequence of noisy transcription remains unclear. Regardless, open chromatin appears to be essential for the stem cell state and pluripotency: Enforcing tighter binding of chromatin proteins prevents ES cell differentiation (Meshorer et al. 2006), and knockdown of Chd1, a chromatin remodeling protein that maintains an open chromatin 
configuration in ES cells, disrupts pluripotency (GasparMaia et al. 2009).

\section{Chromatin state in generating transcriptional competence}

Transcriptional competence of genes is generated by relaxation of repressive chromatin structure at their corresponding promoters or enhancers. This is achieved mainly through the binding of trans-acting factors and subsequent histone modifications. Once the pioneer transcription factor gains access to the binding site, it might recruit several histone-modifying enzymes to further open and modify the local chromatin structure. This opening of chromatin allows other players to access the regulatory binding sites. Hyperacetylation of histones at promoters and enhancers confers an open chromatin conformation, generating transcriptional competence. ES cells seem to have higher levels of global histone acetylation compared with differentiated cells (Efroni et al. 2008; Krejci et al. 2009), potentially enabling the maintenance of transcriptional competence across their genome.

In an earlier work, Xu et al. (2007) provided evidence for active marking of tissue-specific enhancers by pioneer transcription factors, thus enabling transcriptional competence. Xu et al. (2007) showed that, in ES cells, localized marking occurs at enhancers of genes destined to be expressed at a later developmental stage. However, the significance of the marks and the identity of the responsible factors were not entirely clear. Now, Xu et al. (2009) provide evidence that unmethylated windows at enhancers are essential for the generation of transcriptional competence in pluripotent cells, and they further identify at least one prominent factor, FoxD3, that participates in enhancer marking.

\section{Active marking of tissue-specific enhancers in ES cells}

\section{The role of $C p G$ methylation in gene regulation}

Cytosine methylation of genomic CpG dinucleotides is a common epigenetic modification in mammals. CpG dinucleotides are unevenly distributed in mammalian genomes and are frequently associated with gene promoters in stretches that are termed "CpG islands." The majority of all known housekeeping genes and many of the tissue-specific genes contain CpG islands in their promoters (Strathdee et al. 2004). Cells often use methylation of $\mathrm{CpG}$ islands to repress gene expression of tissuespecific genes. CpG methylation is implicated in a number of different functions in cells, such as imprinting, $\mathrm{X}$-chromosome inactivation, tissue-specific transcription, development, and disease (Strathdee et al. 2004).

In a study of promoter usage and structure in stem cells, it has been found that "stemness" genes use on average more CpG-rich promoters than developmental genes (Edwards et al. 2008). Global mapping of promoter methylation patterns revealed that promoters of most pluripotency and housekeeping genes are unmethylated in ES cells, while promoters of developmental genes are methylated, and, as a consequence, repressed (Fouse et al. 2008). Interestingly, ES cells, but not differentiated cells, also contain methylation at CpA and CpT dinucleotides, although at very low levels (Ramsahoye et al. 2000). Very recently, cytosine methylation was compared between ES cells and fetal fibroblasts at a single-base resolution. Intriguingly, in contrast to fibroblasts, a quarter of the methylation found in ES cells seems to be present in a non-CpG context (Lister et al. 2009). These reports indicate that DNA methylation is unique in ES cells, and that pluripotent cells might be using a different gene regulation mechanism that is yet to be identified.

\section{An unmethylated window at the Alb1 enhancer}

Building on their own earlier work (Xu et al. 2007), which demonstrated that the Ptcra and Alb1 enhancers (but not promoters) are marked by an unmethylated CpG window in undifferentiated ES cells, Xu et al. (2009) now identify FoxD3 as the essential factor for the establishment of the unmethylated mark. Xu et al. (2009) show that overexpression of FoxD3 in mouse embryonic fibroblasts (MEFs) is sufficient to establish the unmethylated window, possibly by opening chromatin locally at the Alb1 enhancer. Xu et al. (2009) also compared the methylation status of the $A l b 1$ enhancer in two induced pluripotent stem (iPS) cell lines with the parental MEFs. Xu et al. (2009) found that the Alb1 enhancer CpG methylation was lost during reprogramming. Expression level measurements of several Fox family members in undifferentiated ES cells, definitive endoderm derived from ES cells, and hepatocytes revealed that FoxD3 is expressed primarily in ES cells, while FoxA1 and FoxA2 are highly abundant in the differentiated cells only. Based on these data, Xu et al. (2009) propose that FoxD3 acts as a "placeholder" for FoxA1 and FoxA2 until these genes are activated during endodermal differentiation. These findings may explain some of the roles that FoxD3 plays in stem cell selfrenewal and pluripotency (Liu and Labosky 2008).

$\mathrm{Xu}$ et al. (2009) next examined the capacity of iPS cells to demethylate a premethylated enhancer-promoterreporter-insulator plasmid (Xu et al. 2007). Xu et al. (2009) used their previously characterized enhancer of the Ptcra gene, which is expressed in thymocytes. Xu et al. (2009) show the exclusive establishment of the enhancer mark in iPS cells, but not in unrelated MEFs, in line with their previous findings (Xu et al. 2007). Xu et al. (2009) suggest that tissue-specific enhancers may be marked in pluripotent cells to prevent them from being packaged into repressive chromatin.

To further examine the relationship between chromatin structure and the establishment of enhancer marks at tissue-specific genes, Xu et al. (2009) studied another unrelated macrophage/dendritic cell-specific enhancer, $I 112 b$. The $I 112 b$ enhancer is unmethylated in both ES cells and macrophages, but exhibits DNase I hypersensitivity in only the latter, suggesting that the establishment of the enhancer mark occurs at the pluripotent stage. Once again, Xu et al. (2009) show that the susceptibility to the establishment of the mark is lost at a very early 
stage in development. When Xu et al. (2009) incorporated the $I 112 b$ enhancer into a bacterial artificial chromosome (BAC) to test the establishment of the mark in a more native context, the mark readily established in ES cells, but not in differentiated cells, and supported proper subsequent gene expression when ES cells were allowed to differentiate. These results suggest that chromatin structure in ES cells is involved in and is important for the regulation of enhancer marking.

$\mathrm{Xu}$ et al. (2009) further found that the epigenetic state of the premethylated plasmid in differentiated cells resembles the repressed chromatin state of differentiated cells, indicating that chromatin structure likely plays a major role in the resistance of differentiated cells to the establishment of enhancer marks. To test this, Xu et al. (2009) targeted, using RNAi technology, a methyl-CpGbinding protein-containing complex, NuRD, that maintains repressive chromatin structure at methylated promoters (Kaji et al. 2006). When Xu et al. (2009) inhibited the expression of the NuRD component Mi-2 $\beta$ in thymocytes, they found an increase in demethylation of the stably integrated Ptcra enhancer. These results indicate that chromatin structure plays an important role in the establishment of unmethylated windows at tissuespecific enhancers during early development.

The investigators' next goal was to identify the DNA regions that regulate enhancer activity. Xu et al. (2009) created a series of substitution and deletion mutants at the Ptcra enhancer and transfected the mutated premethylated enhancer-promoter-reporter-insulator plasmids into ES cells. As expected, some of the mutants exhibited reduced susceptibility to the establishment of the unmethylated window, but, intriguingly, several mutations resulted in enhanced susceptibility. It appears that, during early development, establishment of unmethylated windows at tissue-specific enhancers is dependent on transcription factor binding, and is subject to both positive and negative regulation. Taken together, these results demonstrate that pluripotent cells retain transcriptional competence through the establishment and maintenance of an unmethylated mark at tissue-specific enhancers (Fig. 1).

\section{Implications for reprogramming}

Although reprogramming of somatic cells from different sources is routinely done now, the efficiency of the
Pluripotency-related gene

(A) Pluripotent cel

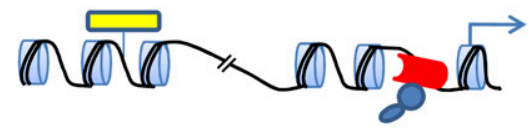

(B) Multipotent progenitor cell
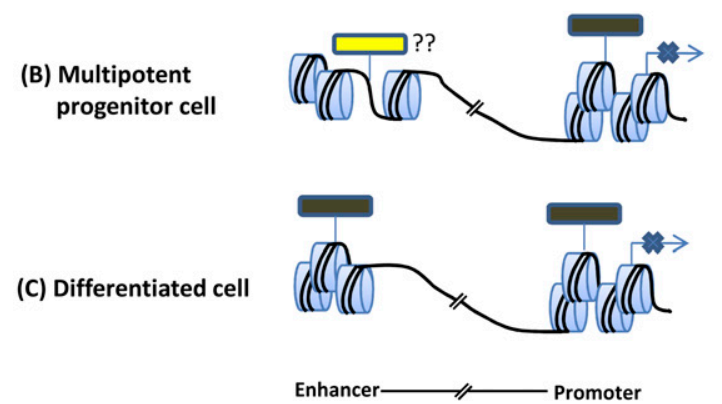

Tissue-specific gene
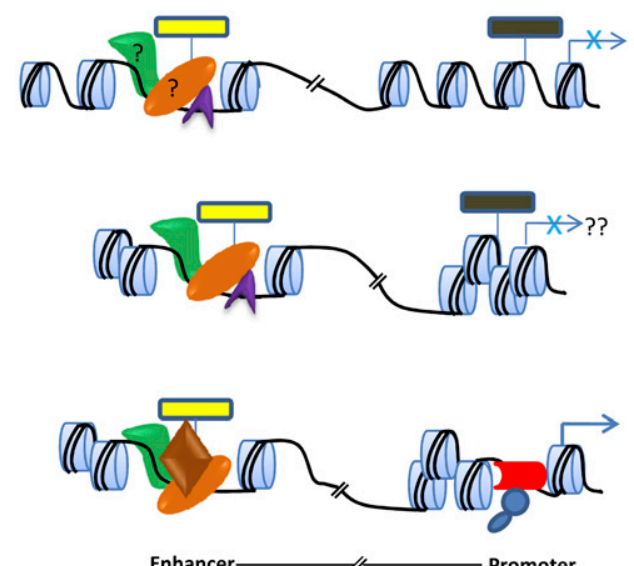

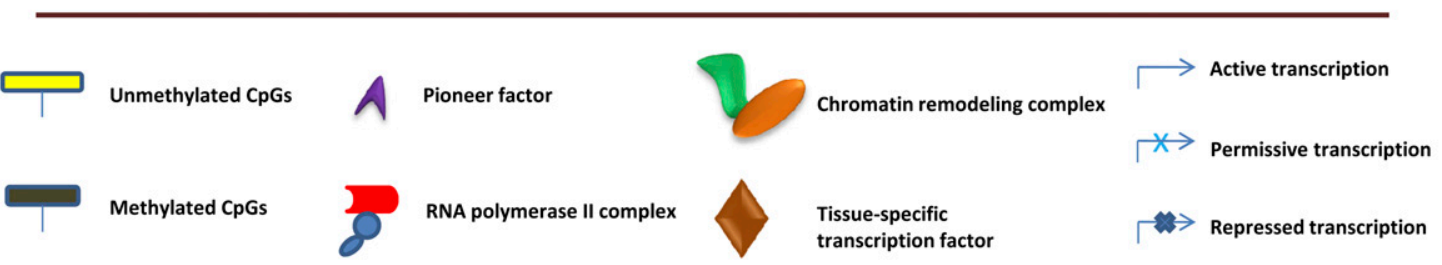

Figure 1. Epigenetic enhancer regulation during differentiation/development. (A) Enhancer and promoter modifications of a pluripotencyrelated gene and a tissue-specific gene in pluripotent stem cells. (Right) Chromatin is open and readily accessible in these cells, and pioneer factors can gain access to their binding sites easily and maintain an unmethylated window at tissue-specific gene enhancers. A typical pluripotency-related gene enhancer such as Oct4 contains less CpG methylation in pluripotent cells in comparison with differentiated cells (Hattori et al. 2004). (B) In multipotent progenitor cells, chromatin accessibility is more restricted and pluripotency gene expression is shut down. Enhancer methylation status of pluripotency-related genes is not clear. Chromatin remodelers and other lineage-specific factors may bind the tissue-specific enhancer and keep the gene in a poised state. $(C)$ In differentiated cells, chromatin is more tightly packed and pluripotency genes are actively repressed. However, at tissue-specific gene enhancers, the chromatin is kept in an open conformation due to active marking by transcription factors. Binding of tissue-specific transcription factors to tissue-specific enhancers ensures proper transcription. 
process remains relatively low. Obviously, extensive chromatin remodeling and genome-wide epigenetic modifications are required for proper reprogramming, so this comes as no surprise. However, recent studies show that these epigenetic barriers are surmountable (Hochedlinger and Plath 2009; Yamanaka 2009). One of the barriers to reprogramming is DNA methylation and demethylation, which must occur at developmental gene promoters and enhancers during reprogramming.

As discussed earlier in the case of transcription, stochasticity is likely the norm in pluripotent stem cells, rather than a one-off phenomenon. This probably applies for other areas of stem cell biology as well; stochastic down-regulation of factors maintaining DNA methylation might also contribute to the demethylation observed during reprogramming. Cells with low expression of these factors might be reprogrammed more readily than others, possibly partly explaining the low efficiency of the process. Stochastic enhancer action might also be responsible for the noisy transcription observed in ES cells (Fiering et al. 2000; Efroni et al. 2008).

This study raises some important questions. For example, it is not clear how enhancer DNA demethylation is maintained in ES cells and is achieved during reprogramming. In the absence of a bona fide DNA demethylase, it is easier to envisage passive DNA demethylation, which might occur during early development as well as during cellular reprogramming, but this assumption awaits proof. It is also not clear why only some of the tissuespecific enhancers are marked but not others. This is an intriguing question, because it could possibly explain why ES cells seem to be more efficient in making some lineages, such as neuroectoderm (Alvarez-Buylla et al. 2001), but not others. The relationship between enhancer methylation and expression is also not entirely understood; the Ptcra enhancer, for example, is unmethylated in ES cells-likely for the sake of transcriptional competencebut it remains unmethylated in MEFs, yet not expressed. Finally, now that FoxD3 has been identified to regulate the enhancer mark of the Alb1 enhancer in pluripotent cells, it calls for the identification of multiple additional factors potentially performing similar tasks, acting on enhancers of other tissue-specific genes. Revealing these factors will add another dimension to the genetic network operating in pluripotent cells.

\section{Acknowledgments}

We thank S. Efroni for critically reviewing this manuscript. E.M. is a Joseph H. and Belle R. Braun Senior Lecturer in Life Sciences and is supported by the Israel Science Foundation (ISF 215/07 and 943/09), the European Union (IRG-206872), and an Alon Fellowship. E.V.S.R.R. is a Marie Curie ITN fellow (Nucleosome4D).

\section{References}

Alvarez-Buylla A, Garcia-Verdugo JM, Tramontin AD. 2001. A unified hypothesis on the lineage of neural stem cells. Nat Rev Neurosci 2: 287-293.

Azuara V, Perry P, Sauer S, Spivakov M, Jorgensen HF, John RM, Gouti M, Casanova M, Warnes G, Merkenschlager M, et al.
2006. Chromatin signatures of pluripotent cell lines. Nat Cell Biol 8: 532-538.

Barski A, Cuddapah S, Cui K, Roh TY, Schones DE, Wang Z, Wei G, Chepelev I, Zhao K. 2007. High-resolution profiling of histone methylations in the human genome. Cell 129: 823837.

Bernstein BE, Mikkelsen TS, Xie X, Kamal M, Huebert DJ, Cuff J, Fry B, Meissner A, Wernig M, Plath K, et al. 2006. A bivalent chromatin structure marks key developmental genes in embryonic stem cells. Cell 125: 315-326.

Bhattacharya D, Talwar S, Mazumder A, Shivashankar GV. 2009. Spatio-temporal plasticity in chromatin organization in mouse cell differentiation and during Drosophila embryogenesis. Biophys J 96: 3832-3839.

Blackwood EM, Kadonaga JT. 1998. Going the distance: A current view of enhancer action. Science 281: 60-63.

Cairns BR. 2009. The logic of chromatin architecture and remodelling at promoters. Nature 461: 193-198.

Chang HH, Hemberg M, Barahona M, Ingber DE, Huang S. 2008. Transcriptome-wide noise controls lineage choice in mammalian progenitor cells. Nature 453: 544-547.

Chen X, Xu H, Yuan P, Fang F, Huss M, Vega VB, Wong E, Orlov $\mathrm{YL}$, Zhang $\mathrm{W}$, Jiang J, et al. 2008. Integration of external signaling pathways with the core transcriptional network in embryonic stem cells. Cell 133: 1106-1117.

Cirillo LA, Lin FR, Cuesta I, Friedman D, Jarnik M, Zaret KS. 2002. Opening of compacted chromatin by early developmental transcription factors HNF3 (FoxA) and GATA-4. Mol Cell 9: 279-289.

Edwards YJ, Bryson K, Jones DT. 2008. A meta-analysis of microarray gene expression in mouse stem cells: Redefining stemness. PLoS One 3: e2712. doi: 10.1371/journal.pone. 0002712. .

Efroni S, Duttagupta R, Cheng J, Dehghani H, Hoeppner DJ, Dash C, Bazett-Jones DP, Le Grice S, McKay RD, Buetow $\mathrm{KH}$, et al. 2008. Global transcription in pluripotent embryonic stem cells. Cell Stem Cell 2: 437-447.

Efroni S, Melcer S, Nissim-Rafinia M, Meshorer E. 2009. Stem cells do play with dice: A statistical physics view of transcription. Cell Cycle 8: 43-48.

Fazzio TG, Huff JT, Panning B. 2008. An RNAi screen of chromatin proteins identifies Tip60-p400 as a regulator of embryonic stem cell identity. Cell 134: 162-174.

Fiering S, Whitelaw E, Martin DI. 2000. To be or not to be active: The stochastic nature of enhancer action. Bioessays 22: $381-387$.

Fouse SD, Shen Y, Pellegrini M, Cole S, Meissner A, Van Neste L, Jaenisch R, Fan G. 2008. Promoter CpG methylation contributes to ES cell gene regulation in parallel with Oct4/Nanog, PcG complex, and histone H3 K4/K27 trimethylation. Cell Stem Cell 2: 160-169.

Gaspar-Maia A, Alajem A, Polesso F, Sridharan R, Mason MJ, Heidersbach A, Ramalho-Santos J, McManus MT, Plath K, Meshorer E, et al. 2009. Chd1 regulates open chromatin and pluripotency of embryonic stem cells. Nature 460: 863868.

Guenther MG, Levine SS, Boyer LA, Jaenisch R, Young RA. 2007. A chromatin landmark and transcription initiation at most promoters in human cells. Cell 130: 77-88.

Hanna LA, Foreman RK, Tarasenko IA, Kessler DS, Labosky PA. 2002. Requirement for Foxd3 in maintaining pluripotent cells of the early mouse embryo. Genes \& Dev 16: 2650-2661.

Hattori N, Nishino K, Ko YG, Ohgane J, Tanaka S, Shiota K. 2004. Epigenetic control of mouse Oct-4 gene expression in embryonic stem cells and trophoblast stem cells. I Biol Chem 279: 17063-17069. 
Heintzman ND, Ren B. 2009. Finding distal regulatory elements in the human genome. Curr Opin Genet Dev. doi: 10/1016/ j.gde.2009.09.006.

Ho L, Jothi R, Ronan JL, Cui K, Zhao K, Crabtree GR. 2009. An embryonic stem cell chromatin remodeling complex, esBAF, is an essential component of the core pluripotency transcriptional network. Proc Natl Acad Sci 106: 51875191.

Hochedlinger K, Plath K. 2009. Epigenetic reprogramming and induced pluripotency. Development 136: 509-523.

Kaji K, Caballero IM, MacLeod R, Nichols J, Wilson VA, Hendrich B. 2006. The NuRD component Mbd3 is required for pluripotency of embryonic stem cells. Nat Cell Biol 8: 285-292.

Kalmar T, Lim C, Hayward P, Munoz-Descalzo S, Nichols J, Garcia-Ojalvo J, Martinez Arias A. 2009. Regulated fluctuations in nanog expression mediate cell fate decisions in embryonic stem cells. PLOS Biol 7: e1000149. doi: 10.1371/ journal.pbio.1000149.

Kim J, Chu J, Shen X, Wang J, Orkin SH. 2008. An extended transcriptional network for pluripotency of embryonic stem cells. Cell 132: 1049-1061.

Krejci J, Uhlirova R, Galiova G, Kozubek S, Smigova J, Bartova E. 2009. Genome-wide reduction in H3K9 acetylation during human embryonic stem cell differentiation. I Cell Physiol 219: 677-687.

Lister R, Pelizzola M, Dowen RH, Hawkins RD, Hon G, TontiFilippini J, Nery JR, Lee L, Ye Z, Ngo QM, et al. 2009. Human DNA methylomes at base resolution show widespread epigenomic differences. Nature doi: 10.1038/nature08514.

Liu Y, Labosky PA. 2008. Regulation of embryonic stem cell self-renewal and pluripotency by Foxd3. Stem Cells 26: 2475-2484.

Meshorer E. 2008. Imaging chromatin in embryonic stem cells. In StemBook (ed. The Stem Cell Research Community), StemBook. doi: 10.3824/stembook.1.2.1. http://www.stembook. org.

Meshorer E, Misteli T. 2006. Chromatin in pluripotent embryonic stem cells and differentiation. Nat Rev Mol Cell Biol 7: 540-546.

Meshorer E, Yellajoshula D, George E, Scambler PJ, Brown DT, Misteli T. 2006. Hyperdynamic plasticity of chromatin proteins in pluripotent embryonic stem cells. Dev Cell 10: 105116.

Niwa H, Ogawa K, Shimosato D, Adachi K. 2009. A parallel circuit of LIF signalling pathways maintains pluripotency of mouse ES cells. Nature 460: 118-122.

Pan G, Tian S, Nie J, Yang C, Ruotti V, Wei H, Jonsdottir GA, Stewart R, Thomson JA. 2007. Whole-genome analysis of histone H3 lysine 4 and lysine 27 methylation in human embryonic stem cells. Cell Stem Cell 1: 299-312.

Ramsahoye BH, Biniszkiewicz D, Lyko F, Clark V, Bird AP, Jaenisch R. 2000. Non-CpG methylation is prevalent in embryonic stem cells and may be mediated by DNA methyltransferase 3a. Proc Natl Acad Sci 97: 5237-5242.

Sandelin A, Carninci P, Lenhard B, Ponjavic J, Hayashizaki Y, Hume DA. 2007. Mammalian RNA polymerase II core promoters: Insights from genome-wide studies. Nat Rev Genet 8: 424-436.

Sha K, Boyer LA. 2009. The chromatin signature of pluripotent cells. In StemBook (ed. The Stem Cell Research Community), StemBook. doi: 10.3824/stembook.1.45.1. http://www. stembook.org.

Strathdee G, Sim A, Brown R. 2004. Control of gene expression by $\mathrm{CpG}$ island methylation in normal cells. Biochem Soc Trans 32: 913-915.
Szutorisz H, Dillon N, Tora L. 2005. The role of enhancers as centres for general transcription factor recruitment. Trends Biochem Sci 30: 593-599.

Walker E, Ohishi M, Davey RE, Zhang W, Cassar PA, Tanaka TS, Der SD, Morris Q, Hughes TR, Zandstra PW, et al. 2007. Prediction and testing of novel transcriptional networks regulating embryonic stem cell self-renewal and commitment. Cell Stem Cell 1: 71-86.

Xu J, Pope SD, Jazirehi AR, Attema JL, Papathanasiou P, Watts JA, Zaret KS, Weissman IL, Smale ST. 2007. Pioneer factor interactions and unmethylated $\mathrm{CpG}$ dinucleotides mark silent tissue-specific enhancers in embryonic stem cells. Proc Natl Acad Sci 104: 12377-12382.

Xu J, Watts JA, Pope SD, Gadue P, Kamps M, Plath K, Zaret KS, Smale ST. 2009. Transcriptional competence and the active marking of tissue-specific enhancers by defined transcription factors in embryonic and induced pluripotent stem cells. Genes \& Dev (this issue). doi: 10.1101/gad.1861209.

Yamanaka S. 2009. A fresh look at iPS cells. Cell 137: 13-17.

Yan Z, Wang Z, Sharova L, Sharov AA, Ling C, Piao Y, Aiba K, Matoba R, Wang W, Ko MS. 2008. BAF250B-associated SWI/ SNF chromatin-remodeling complex is required to maintain undifferentiated mouse embryonic stem cells. Stem Cells 26: $1155-1165$.

Zaret KS. 2002. Regulatory phases of early liver development: Paradigms of organogenesis. Nat Rev Genet 3: 499-512. 


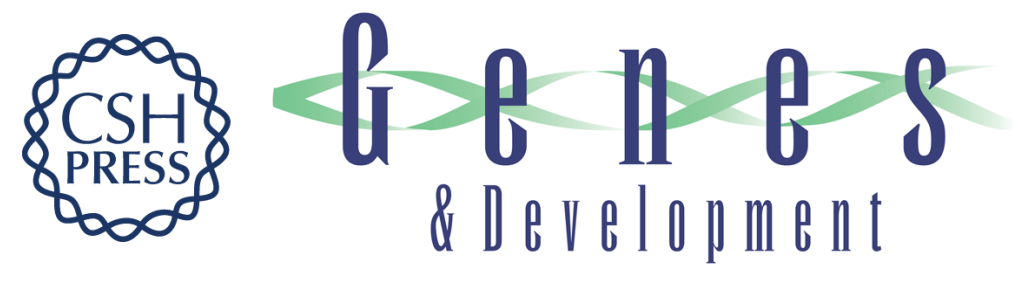

\section{Transcriptional competence in pluripotency}

Edupuganti V.S. Raghu Ram and Eran Meshorer

Genes Dev. 2009, 23:

Access the most recent version at doi:10.1101/gad.1881609

Related Content

References

\section{License}

Email Alerting

Service
This article cites 43 articles, 8 of which can be accessed free at:

http://genesdev.cshlp.org/content/23/24/2793.full.html\#ref-list-1

Articles cited in:

http://genesdev.cshlp.org/content/23/24/2793.full.html\#related-urls

Transcriptional competence and the active marking of tissue-specific enhancers by defined transcription factors in embryonic and induced pluripotent stem cells Jian Xu, Jason A. Watts, Scott D. Pope, et al.

Genes Dev. December, 2009 23: 2824-2838

Receive free email alerts when new articles cite this article - sign up in the box at the top right corner of the article or click here.

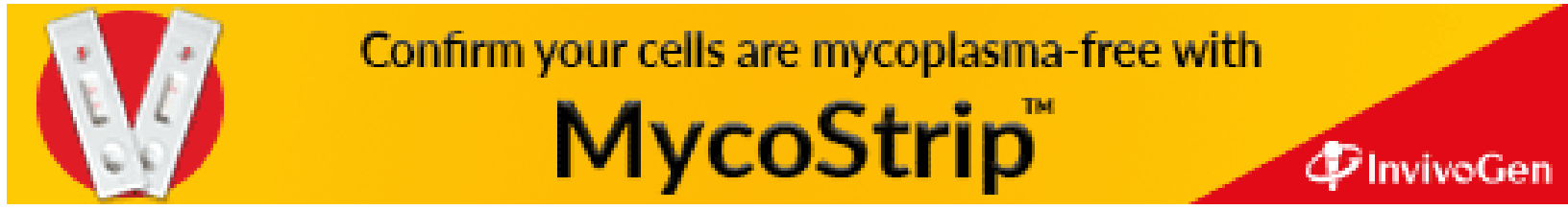

